\title{
Prognosis of schizophrenia spectrum disorder may not be predetermined during early development - the Northern Finland Birth Cohort 1966
}

Nina Rautio, ${ }^{a, b}$ Juha Käkelä, ${ }^{a, c, d}$ Tanja Nordström, ${ }^{a, d}$ Jouko Miettunen, ${ }^{a, c, d, e}$ Sirkka Keinänen-

Kiukaanniemi, ${ }^{a, b}$ Leena Ala-Mursula, ${ }^{a}$ Jaro Karppinen, ${ }^{a, d}$ Matti Penttilä ${ }^{c, d, e}$ and Erika Jääskeläinen ${ }^{a, c, d}$

${ }^{a}$ Center for Life Course Health Research, University of Oulu, P.O. Box 5000, 90014 Oulu, Finland

${ }^{\mathrm{b}}$ Unit of Primary Health Care, Oulu University Hospital, P.O. Box 20, 90029 OYS, Oulu, Finland

${ }^{\mathrm{c}}$ Research Unit of Clinical Neuroscience, Department of Psychiatry, University of Oulu, P.O. Box 5000, 90014 Oulu, Finland

${ }^{\mathrm{d}}$ Medical Research Center Oulu, Oulu University Hospital and University of Oulu. P.O. Box 5000, 90014 Oulu, Finland

${ }^{\mathrm{e}}$ Department of Psychiatry, Oulu University Hospital P.O. Box 20, 90029 OYS, Oulu, Finland

Correspondence concerning this article should be addressed to Nina Rautio, e-mail: nina.rautio@oulu.fi, telephone: +358 40672 4344; fax: +358 85375661

E-mail addresses: juha.kakela@ student.oulu.fi, tanja.nordstrom@oulu.fi, jouko.miettunen@oulu.fi,sirkka.keinanen-kiukaanniemi@oulu.fi, leena.alamursula@oulu.fi,jaro.karppinen@oulu.fi,matti.penttila@oulu.fi,erika.jaaskelainen@oulu.fi Word count: manuscript 2989/3000, abstract 247/250 


\section{Abstract}

Background: Little is known about whether factors during the first years of life predict later outcomes in schizophrenia spectrum disorder (SSD). As part of the Northern Finland Birth Cohort 1966, we examined if prospectively collected early parenthood-related and developmental factors predict employment and hospitalization in individuals with and without SDD.

Methods: Overall, 161 individuals with SSD and 10116 without SSD were included in the study. Outcomes were analysed at age of 44-45 years, defining "employment" as being employed for at least $25 \%$ of working days and "hospitalization" as having psychiatric hospitalization at least once during the last two years of follow-up. Maternal age, wantedness of pregnancy, grand multiparity, parental psychoses, birth weight, birth height, age of standing up and standing and walking without support were analysed as predictors. Results: Of the individuals with SSD, only $11.2 \%$ were employed, although $77.6 \%$ remained not hospitalized. In individuals with SSD, only young maternal age was associated with lower probability (OR $0.25, \mathrm{Cl} 0.08-0.77$ ) of being non-hospitalized after controlling for sex and onset age of illness. Among persons without SSD, almost all parenthood-related and developmental factors were related to employment, while grand multiparity and parental psychosis were related to hospitalization after controlling for sex. Conclusions: Only one of the early parenthood-related and developmental factors analysed in this study predicted outcome in individuals with SSD, while among those without SSD almost all factors were related to employment. Thus, prognosis of SSD does not seem to be predetermined much by early development.

Keywords: schizophrenia, employment, hospitalization, early predictors 


\section{Introduction}

Deviances in development and environment during early years of life increase the risk of schizophrenia (Laurens et al., 2015; Matheson et al., 2011), but their effect on prognosis after the illness onset is poorly known. There are hypotheses suggesting that some risk factors for schizophrenia such as delayed development are also prognostic indicators for patients with established illness. For example Johnstone et al. (1995) stated that "the most malignant form of schizophrenia is neurodevelopmental." The more specific hypothesis was presented by Murray et al. (1992): “congenital schizophrenia is a consequence of aberrant brain development during fetal and neonatal life. Such patients show structural brain changes and cognitive impairment, and in their male predominance, early onset, and poor outcome, they reflect Kraepelin's original description of dementia praecox.” Regarding the progressive neurodevelopmental hypothesis of schizophrenia (Douaud et al., 2014; Nour and Howes, 2015), one would expect that abnormal neurodevelopment would continue after the illness onset, and thus early risk factors of illness would associate also to poorer prognosis. If there would be such association, this could indicate that the prognosis of schizophrenia is programmed already during fetal period and early development.

So far, early developmental and environmental predictors of outcomes in schizophrenia have been analysed rarely, and most studies have focused on the predictors occurring later at life. For example, previous poor working history (Marwaha and Johnson, 2004), family history of psychosis (Käkelä et al., 2014), later illness onset, longer duration of illness (Marwaha et al., 2009; Ran et al., 2011) and lower economic status of the family (Ran et al., 2011) predicted poorer employment status. Predictors of longer or more frequent psychiatric hospital admission include higher dosages of antipsychotics, greater proportion of prior 
hospitalization, earlier illness onset, lower school performance (Uggerby et al., 2011), lower social function (Olfson et al., 2011) and psychiatric co-morbidity (Lang et al., 2010).

In the very few studies of early developmental and environmental predictors of outcomes in schizophrenia, these factors mostly did not predict outcomes. The history of obstetric complications was not related to hospitalizations (Smith et al., 1995). Later achievement of learning to stand or walk and becoming potty-trained were not associated with poorer outcome at 35 years (Jääskeläinen et al., 2008). Only pre-natal exposure to environmental adversities increased the risk of re-hospitalization (Levine et al., 2014) and patients born in winter have had shorter periods of psychiatric hospitalization during first admission (Rodrigo et al., 1991). Comparative studies on developmental and environmental predictors of outcomes in schizophrenia and individuals without schizophrenia, are also lacking.

The aim of this study was to examine prospectively collected early parenthood-related and developmental factors as predictors of prognosis (i.e. register-based employment and hospitalization outcomes) in schizophrenia spectrum disorder (SSD) in years after the illness onset and to compare the results with individuals without SSD. The analysed variables were same factors, such as high maternal age, unwantedness of the pregnancy, grand multiparity, parental psychosis, high weight and low height at birth, and later achievement of standing up and standing and walking without support that increased the risk of schizophrenia in this same birth cohort sample until the ages of 44 (Keskinen et al., 2013) and 46 years (Keskinen et al., 2015). We hypothesized that early parenthood-related and developmental risk factors are related to a lower level of employment and a higher level of hospitalization at midlife among those with SSD. 


\section{Methods}

\subsection{Sample}

This study is based on the NFBC 1966 study, which is a general population cohort study concerning 12068 pregnant women and their 12058 live-born children in 1966 in the provinces of Oulu and Lapland (Rantakallio, 1969). This study includes individuals who were alive at the age of 16 years and living in Finland $(n=11017)$. By the end of the follow-up on 31 December 2011, at the age of 45, overall 84 of them denied the use of their data, 386 had died, and 270 had emigrated and thus were excluded from the study, leading to a sample of 10 277. Permission to gather data was obtained from the Ministry of Social and Health Affairs and the study design was approved by the Ethical Committee of the Northern Ostrobothnia Hospital District.

Diagnosis of SSD was based on an individual's presence in the national register from 1982 to 2006 (i.e. schizophrenia (ICD-8 \& ICD-9: 295, ICD-10: F20), schizophreniform disorder (ICD-8 \& ICD-9: 2954), schizoaffective disorder (ICD-8 \& ICD-9: 2957, ICD-10: F25) or delusional order (ICD-8 \& ICD-9: 297 and ICD-10: F22)), as well as follow-up of at least five years since the age of illness onset. By the end of the year 2006, at the age of 40 years, $1.6 \%$ of 10277 individuals ( $\mathrm{n}=161 ; 90$ men and 71 women) had SSD and all the rest 10116 persons were without SSD. The included registers were the Care Register for Health Care (CRHC; formerly the Finnish Hospital Discharge Register), Specialized Outpatient Care Register (SOCR; information available since 1998), Register on Pensions from the Finnish Centre for Pensions (FCP), and registers from the Social Insurance Institution of Finland (SII; 
reimbursable medicine until the end of 2005, disability pension until the end of 2000 and sick-days until the end of 1999).

Outcomes were evaluated for persons with and without SSD from 1 January 2010 to 31 December 2011 at the age of 44-45 years. The length of follow-up since the onset of illness among those with SSD was on average 17.5 years: 25 (15.5\%) had 5-9 years followup, 77 (47.8\%) had 10-19 years follow-up and 59 (36.6\%) had 20 years or longer follow-up.

\subsection{Measures of outcomes}

Employment status. Information on disability pension and working days during the last two years at the end of the follow-up were included in the employment status. Disability pension in Finland is based on a medical certificate, it can be granted (until further notice as a full or a partial disability pension or for a temporary period as a full or partial cash rehabilitation benefit) if a persons's working capacity has been reduced for at least one year (Disability Pension, 2014). Working for a limited pay is allowed. If a person had received these benefits, she/he was considered as receiving a disability pension. Because of low number of working days among those with SSD we defined subjects as 'employed' if they had been working for at least $25 \%$ of the working days (Table 1) and all the rest were considered as 'not employed'.

Data concerning disability pensions were obtained from the FCP and SII. Although the disability pensions are usually earnings-related and covered by the employer's or entrepreneur's pension provider and therefore registered in FCP (Disability pension, 2014), individuals can obtain disability pension from the SII, if other disability pension or 
reimbursement does not meet a specified limit (Social Insurance Institution, 2012 ). In practice those persons who fell ill early and did not enter working life were registered in the SII (data available until the end of 2000), while those who had been working were found in the register of the FCP (until the end of 2011). Employment status was based on the register obtained from the FCP until 2011.

Hospitalization. We analysed the presence of psychiatric hospitalizations during the two years at the end of follow-up. All the treatment periods with psychiatric diagnoses in psychiatric hospitals were gathered until the end of 2011 from the CRHC.

Good outcome. We combined the two aforementioned outcomes to define good outcome: employment for at least $25 \%$ of the working days and no hospitalization during the last two years of follow-up.

\subsection{Predictors}

Early parenthood-related and developmental factors and their classifications were based on earlier literature to present factors that increase the risk of schizophrenia (Keskinen et al., 2013; Keskinen et al., 2015).

Maternal age was classified into $<20,20-35$ and $>35$ years (Keskinen et al., 2013) and information was obtained from the population register (Miller et al., 2011).

Wantedness of pregnancy was dichotomized into wanted/mistimed and unwanted (Myhrman et al., 1996) and grand multiparity was classified as "no" ( $<6$ children) and "yes" $(\geq 6$ children) (Kemppainen et al., 2000). Information was obtained from the mother's interviews 
conducted by nurses in antenatal clinics using questionnaires between 1965 and 1966 (Rantakallio, 1969).

Parental (maternal/paternal) psychosis was considered "yes" if one of the parents had any psychosis (i.e. ICD-8: 295-299; ICD-9: 295, 2961E, 2962E, 2963E, 2964E, 2967 and 297299; ICD-10: F20 and F22-F29) based on the CRHC (former Finnish Hospital Discharge Register, 1972-2012), Specialized Outpatient Care Register (1998-2012), Register of Primary Health Care Visits (2011-2012), and FCP (disability pensions, 1964-2011). Birth weight (g) measured to the nearest $100 \mathrm{~g}$, was categorized into $<2500 \mathrm{~g}, 2500-4500 \mathrm{~g}$ and $>4500 \mathrm{~g}$ and height at birth $(\mathrm{cm})$ into $\leq 46 \mathrm{~cm}, 47-53 \mathrm{~cm}$, and $\geq 54 \mathrm{~cm}$ (Moilanen et al., 2010). Information was based on the delivery records between 1965 and 1966 (Rantakallio, 1969).

The age of achievement of standing up, standing up without support and walking without support was examined in months as a continuous variable (Keskinen et al., 2015) and information was gathered from regular visits to Finnish child welfare clinics (Pillas et al., 2014).

\subsection{Background factors and covariates}

Sex, age at the onset of SSD, mother's education and marital status during the pregnancy were used as background variables. The onset of SSD was based on the date of beginning of the registry entry of any psychosis diagnosis (Isohanni et al., 1997; Moilanen et al., 2003). Age at the onset of SSD was classified into <20, 20-35 and >35 years based on the earlier studies (Linke et al., 2015; Nowrouzi et al., 2015). Mother's education was classified into 08 and 9 years or more, and marital status to "married" and "single/divorced/widowed" and 
were obtained from the interviews conducted by nurses with the help of questionnaires (Rantakallio, 1969).

\subsection{Statistical analyses}

Statistical analyses were conducted using IBM SPSS Statistics version 22 [SPSS, Inc., 1989, 2013]. Cross-tabulation, $\chi^{2}$-test, Fisher's exact test and $t$-test for independent samples were used to study the association of sex, age of onset of SSD and early parenthood-related and developmental factors with employment and hospitalization. Furthermore, Mann-Whitney test was used to check the results of t-tests, because of skewedness in some cases in continuous variables. Binary logistic regression models were conducted to study the association between early parenthood-related and developmental factors and employment and hospitalization after adjustment for sex and age of onset of SSD in individuals with SSD and after adjustment for sex in persons without SSD.

\section{Results}

\subsection{Outcomes}

Altogether, $11.2 \%$ of individuals with SSD were employed, four of them simultaneously receiving disability pension. However, $77.6 \%$ remained not hospitalized during these last two years of follow-up (Table 2). Subjects with diagnosis of schizophrenia were less often employed and more often hospitalized than subjects with other SDD diagnosis (Table 3). Persons fulfilling both criteria of being employed and not hospitalized were exactly the same persons as those employed, since all who were employed had no hospital treatments 
(Table 2). Among persons without SSD, 72.1\% were employed, 98.6\% were not hospitalized (Table 2) and $71.7 \%$ fulfilled both criteria.

\subsection{Predictors of outcomes}

None of the early parenthood-related and developmental factors were associated with employment status in individuals with SSD (Tables 2 and 4). In individuals without SSD, young maternal age, parental psychosis, lower weight and height (Table 2) and later achievement of standing up, standing up without support and walking without support (Table 4) were related to lower probability of being employed after controlling for sex (Table 5). However, among those with with SSD, young maternal age was related to hospitalization (Table 2) after controlling for sex and age at the onset of illness (Table 5). Among persons without SSD, grand multiparity and parental psychosis were associated with hospitalization (Table 2) after controlling for sex (Table 5).

\section{Discussion}

\subsection{Main results}

In SSD, none of the early parenthood-related and developmental factors were associated with employment status. However, young maternal age was related to individuals' hospitalization even after controlling for sex and onset age of illness. Instead, among those without SSD family-related and developmental factors were more often related to outcomes, especially employment after controlling for sex. Based on these results, risk factors of schizophrenia may not necessarily be also prognostic factors in SSD. 
Approximately 17.5 years after illness onset, only $11 \%$ of individuals with SSD were employed, yet $78 \%$ were not hospitalized during the last two years of follow-up. While we defined good outcome as being employed for at least $25 \%$ of working days but not hospitalized during the last two years of follow-up, we found that these persons were exactly the same persons who were employed.

\subsection{Employment and its predictors}

We did not find association between early parenthood-related and developmental factors and employment in SSD, which was opposite to those without SSD. Low rate of employment in SSD was in line with the results of previous studies showing employment rates of $4 \%-36 \%$ in schizophrenia (Perälä et al., 2008; Marwaha et al., 2007). However, comparison must be conducted cautiously, because of differences in measures of employment. The unemployment rate may correlate with the economy, though it is also possible that it is due to poor functioning in SSD. Compared to those without mental health problems, persons with mental health problems are more often unemployed, and this gap has widened in Europe in 2010 compared to 2006 following the onset of the economic recession (Evans-Lacko et al., 2013). Since the unemployment rate in our data is nearly $90 \%$, poor functioning seems more reasonable explanation than the economy. In earlier study from a Finnish sample with schizophrenia cases over 30 years, the employment rate was 7\% (Perälä et al., 2008). Lack of motivation, low self-esteem, stigmatization, discrimination and fear of losing financial benefits, may also affect the employment rate in schizophrenia (Bevan et al., 2013). Employers may believe that individuals with schizophrenia can only perform low-skilled jobs (Bevan et al., 2013). 


\subsection{Hospitalization and its predictors}

Young maternal age was related to hospitalization among those with SSD, after controlling for sex and onset age of illness. A study concerning adolescents has also shown that a higher maternal age was related to improvement in the severity of schizophrenia symptoms, but this association disappeared after adjustment for sex, diagnosis age, treatment group, paternal age, baseline Positive and Negative Symptoms Scale (PANSS) and prior hospitalization (Opler et al., 2013). Instead, Ekéus et al. (2006) reported that admissions due to schizophrenia were more likely in young persons of older women at childbirth. The results of these studies are difficult to compare with our results, because of differences in the study population, study design and measures used. Young mothers are most often unmarried, have attained low educational qualifications (Boden et al., 2008) and have mainly received public assistance as their primary source of income (Larson, 2004) and this may have an effect on motherhood. Furthermore, about $30 \%$ of adolescent mothers have reported clinically high levels of stress (Larson, 2004).

Our results concerning hospitalization rate are in line with the earlier longitudinal study reporting that $25 \%$ of individuals with schizophrenia were hospitalized for psychiatric causes during the last two years of follow-up (Ganev et al., 2007). While hospitalization is a proxy measure for illness severity (relapse), it is important to notice other factors related to context (Burns, 2007), such as availability of psychiatric beds and outpatient treatment, as an example (World Health Organization 2011). 


\subsection{Implications}

Early parenthood-related and developmental risk factors of schizophrenia (Keskinen et al., 2013; Keskinen et al., 2015) did not predict later outcomes of illness, with the exception of young maternal age. Based on our study, the prognosis of SSD may not be predetermined in early development, and this highlights even more the importance of effective, individualized treatments. Also, it could be that factors nearer the onset of SSD are more important predictors of outcomes than early life factors present years before illness onset. For example, in smaller subsamples of this same NFBC 1966 cohort, being single (Miettunen et al., 2007), more severe symptoms of the first episode of schizophrenia (Juola et al., 2013), negative symptoms (Mäkinen et al., 2010) and use of antipsychotics (Moilanen et al., 2013) were associated with poorer outcomes even after years of illness.

Earlier research has found some support for a longitudinal association between childhood motor development and progression of cognitive deficits (Kobayashi et al., 2014), thus speaking for a link between neurodevelopment and potential neuroprogression in schizophrenia (Douaud et al., 2014; Nour and Howes, 2015). Instead, any association between motor development around age 1 year, and outcomes in schizophrenia until age 35 years was not found (Jääskeläinen et al., 2008).

\subsection{Strengths and limitations}

The strength is that NFBC 1966 is a population-based cohort, data concerning employment and hospitalization were based on national registers, follow-up was long and we were able to study early parenthood-related and developmental factors as predictors of outcomes of SSD. Most of these variables have not been analysed as predictors of outcomes, and there are not 
many samples allowing a similar long-lasting prospective study starting already prenatally and extending to midlife. The limitations include the diagnosis of SSD being based on registers, so our study does not include persons who have not received treatment. Our sample of individuals with SSD was small and we used very loose criteria when defining employment, which was not very relevant to subjects without SSD. We could not study, for example, early exposure to environmental adversities as predictors of outcomes (Levine et al., 2014), because of lack of information.

\subsection{Conclusions}

The early parenthood-related and developmental risk factors for schizophrenia did not predict later outcomes in SSD, with one exception. Compared to persons without SSD, persons with SSD did not show normative associations between early parenthood-related and developmental risk factors and later outcomes at midlife studied here.

\section{Conflicts of interest}

None.

\section{Contributors}

EJ and JM designed the study. TN and NR undertook the statistical analyses. NR wrote the first version of the manuscript with the help of JK. All authors contributed to and approved the final manuscript. 


\section{Acknowledgements}

This research was supported in part by grants from the Academy of Finland [\#132071, \#268336, \#278286], the Sigrid Jusélius Foundation, the Jalmari and Rauha Ahokas Foundation, the Northern Finland Health Care Support Foundation, and the Brain and Behavior Research Foundation.

\section{References}

Bevan, S., Gulliford, J., Steadman, K., Taskila, T., Thomas, R., Moise, A., 2013. Working with schizophrenia: Pathways to employment, recovery \& inclusion. The Work Foundation, Lancaster University. 1-134. Retrieved from http://www.theworkfoundation.com/downloadpublication/report/330_working_with_schizop hrenia.pdf.

Boden, J.M., Fergusson, D.M., John Horwood, L., 2008. Early motherhood and subsequent life outcomes. J. Child Psychol. Psychiatry 49 (2) 151-160.

Burns, T., 2007. Hospitalisation as an outcome measure in schizophrenia. Br. J. Psychiatry 191 (SUPPL. 50) s37-s41.

Disability Pension, 2014. Security in the Event of Disability 26-5-2014. Retrieved $28^{\text {th }}$ May 2015, from https://www.tyoelake.fi/en/erilaisiaelakkeita/tyokyvyttomyyselake/Pages/default.aspx.

Douaud, G., Groves, A.R., Tamnes, C.K., Westlye, L.T., Duff, E.P., Engvig, A., Walhovd, K.B., James, A., Gass, A., Monsch, A.U., Matthews, P.M., Fjell, A.M., Smith, S.M., Johansen-Berg, H., 2014. A common brain network links development, aging, and vulnerability to disease. Proc. Natl. Acad. Sci. U S A 111 (49) 17648-17653.

Ekéus, C., Olausson, P.O., Hjern, A., 2006. Psychiatric morbidity is related to parental age: A national cohort study. Psychol. Med. 36 (2) 269-276.

Evans-Lacko, S., Knapp, M., McCrone, P., Thornicroft, G., Mojtabai, R., 2013. The Mental Health Consequences of the Recession: Economic Hardship and Employment of People with Mental Health Problems in 27 European Countries. PLOS One DOI: 10.1371/journal.pone.0069792

Ganev, K., Onchev, G., Ivanov, P., 2007. RApyD: Sofia Bulgaria, in: Hopper, K., Harrison, G., Janca, A., Sartorius, N. (Eds.), Recovery from schizophrenia. An International 
Perspective. A Report from the WHO collaborative project. The International study of schizophrenia. Oxford University Press, New York, pp. 227-239.

Isohanni, M., Mäkikyrö, T., Moring, J., Räsänen, P., Hakko, H., Partanen, U., Koiranen, M., Jones, P., 1997. A comparison of clinical and research DSM-III-R diagnoses of schizophrenia in a Finnish national birth cohort. Clinical and research diagnoses of schizophrenia. Soc.

Psychiatry Psychiatr. Epidemiol. 32 (5) 303-308.

Jääskeläinen, E., Miettunen, J., Veijola, J., McGrath, J.J., Murray, G.K., Jones, P.B., Isohanni, M., 2008. Associations between early development and outcome in schizophrenia A 35-year follow-up of the Northern Finland 1966 Birth Cohort. Schizophr. Res. 99 (1-3) 2937.

Johnstone, E.C., Frith, C.D., Lang, F.H., Owens, D.G.C., 1995. Determinants of the extremes of outcome in schizophrenia. Br. J. Psychiatry 167 (5) 604-609.

Juola, P., Miettunen, J., Veijola, J., Isohanni, M., Jääskeläinen, E., 2013. Predictors of short and long-term clinical outcome in schizophrenic psychosis - the Northern Finland 1966 Birth Cohort study. Eur. Psychiatry 28 (5) 263-268.

Käkelä, J., Panula, J., Oinas, E., Hirvonen, N., Jääskeläinen, E., Miettunen, J., 2014. Family history of psychosis and social, occupational and global outcome in schizophrenia: A metaanalysis. Acta Psychiat. Scand. 130, 269-278.

Kemppainen, L., Mäkikyrö, T., Jokelainen, J., Nieminen, P., Järvelin, M.-R., Isohanni, M., 2000. Is grand multiparity associated with offsprings' hospital-treated mental disorders? A 28-year follow-up of the North Finland 1966 birth cohort. Soc. Psychiatry Psychiatr. Epidemiol. 35 (3) 104-108.

Keskinen, E., Marttila, A., Marttila, R., Jones, P.B., Murray, G.K., Moilanen, K., KoivumaaHonkanen, H., Mäki, P., Isohanni, M., Jääskeläinen, E., Miettunen, J., 2015. Interaction between parental psychosis and early motor development and the risk for schizophrenia in a general population birth cohort. Eur. Psychiatry 30 (6) 719-727.

Keskinen, E., Miettunen, J., Koivumaa-Honkanen, H., Mäki, P., Isohanni, M., Jääskeläinen, E., 2013. Interaction between parental psychosis and risk factors during pregnancy and birth for schizophrenia - The Northern Finland 1966 Birth Cohort study. Schizophr. Res. 145 (1-3) $56-62$.

Kobayashi, H., Isohanni, M., Jääskeläinen, E., Miettunen, J., Veijola, J., Haapea, M., Järvelin, M.-R., Jones, P.B., Murray, G.K., 2014. Linking the developmental and degenerative theories of schizophrenia: Association between infant development and adult cognitive decline. Schizophr. Bull. 40 (6) 1319-1327.

Lang, K., Meyers, J.L., Korn, J.R., Lee, S., Sikirica, M., Crivera, C., Dirani, R., Menzin, J., 2010. Medication adherence and hospitalization among patients with schizophrenia treated with antipsychotics. Psychiatr. Serv. 61 (12) 1239-1247. 
Larson, N.C., 2004. Parenting stress among adolescent mothers in the transition to adulthood. Child Adolesc. Social Work J. 21 (5) 457-476.

Laurens, K.R., Luo, L., Matheson, S.L., Carr, V.J., Raudino, A., Harris, F., Green, M.J., 2015. Common or distinct pathways to psychosis? A systematic review of evidence from prospective studies for developmental risk factors and antecedents of the schizophrenia spectrum disorders and affective psychoses. BMC Psychiatry. 15, 205.

Levine, S.Z., Levav, I., Yoffe, R., Pugachova, I., 2014. The effects of pre-natal-, early-lifeand indirectly-initiated exposures to maximum adversities on the course of schizophrenia. Schizophr. Res. 158 (1-3) 236-240.

Linke, M., Jankowski, K., Ciołkiewicz, A., Jędrasik-Styła, M., Parnowska, D., Gruszka, A., Denisiuk, M., Jarema, M., Wichniak, A., 2015. Age or age at onset? Which of them really matters for neuro and social cognition in schizophrenia. Psychiat. Res. 225 197-201.

Mäkinen, J., Miettunen, J., Jääskeläinen, E., Veijola, J., Isohanni, M., Koponen, H., 2010. Negative symptoms and their predictors in schizophrenia within the Northern Finland 1966 Birth Cohort. Psychiat. Res. 178 (1) 121-125.

Marwaha, S., Johnson, S., 2004. Schizophrenia and employment: A review. Soc. Psychiatry Psychiatr. Epidemiol. 39 (5) 337-349.

Marwaha, S., Johnson, S., Bebbington, P., Stafford, M., Angermeyer, M.C., Brugha, T., Azorin, J.-M., Kilian, R., Hansen, K., Toumi, M., 2007. Rates and correlates of employment in people with schizophrenia in the UK, France and Germany. Br. J. Psychiatry 191 (1) 3037.

Marwaha, S., Johnson, S., Bebbington, P.E., Angermeyer, M.C., Brugha, T.S., Azorin, J.-M., Killian, R., Hansen, K., Toumi, M., 2009. Predictors of employment status change over 2 years in people with schizophrenia living in Europe. Epidemiol. Psichiatr. Soc. 18 (4) 344 351.

Matheson, S.L., Shepherd, A.M., Laurens, K.R., Carr, V.J., 2011. A systematic meta-review grading the evidence for non-genetic risk factors and putative antecedents of schizophrenia. Schizophr. Res. 133 (1-3) 133-142.

Miettunen, J., Lauronen, E., Veijola, J., Koponen, H., Saarento, O., Taanila, A., Isohanni, M., 2007. Socio-demographic and clinical predictors of occupational status in schizophrenic psychoses-follow-up within the Northern Finland 1966 Birth Cohort. Psychiat. Res. 150 (3) 217-225.

Miller, B., Suvisaari, J., Miettunen, J., Järvelin, M.-R., Haukka, J., Tanskanen, A., Lönnqvist, J., Isohanni, M., Kirkpatrick, B., 2011. Advanced paternal age and parental history of schizophrenia. Schizophr. Res. 133 (1-3) 125-132.

Moilanen, J., Haapea, M., Miettunen, J., Jääskeläinen, E., Veijola, J., Isohanni, M., Koponen, H., 2013. Characteristics of subjects with schizophrenia spectrum disorder with and without 
antipsychotic medication - A 10-year follow-up of the Northern Finland 1966 Birth Cohort study. Eur. Psychiatry 28 (1) 53-58.

Moilanen, K., Jokelainen, J., Jones, P.B., Hartikainen, A.-L., Järvelin, M.-R., Isohanni, M., 2010. Deviant intrauterine growth and risk of schizophrenia: A 34-year follow-up of the Northern Finland 1966 Birth Cohort. Schizophr. Res. 124 (1-3) 223-230.

Moilanen, K., Veijola, J., Läksy, K., Mäkikyrö, T., Miettunen, J., Kantojärvi, L., Kokkonen, P., Karvonen, J.T., Herva, A., Joukamaa, M., Järvelin, M.-R., Moring, J., Jones, P.B., Isohanni, M., 2003. Reasons for the diagnostic discordance between clinicians and researchers in schizophrenia in Northern Finland 1966 Birth Cohort. Soc. Psychiatry Psychiatr. Epidemiol. 38 (6) 305-310.

Murray, R.M., O'Callaghan, E., Castle, D.J., Lewis, S.W., 1992. A neurodevelopmental approach to the classification of schizophrenia. Schizophr. Bull. 18 (2) 319-332.

Myhrman, A., Rantakallio, P., Isohanni, M., Jones, P., Rartanen, U., 1996. Unwantedness of a pregnancy and schizophrenia in the child. Br. J. Psychiatry 169 (5) 637-640.

Nour, M.M., Howes, O.D., 2015. Interpreting the neurodevelopmental hypothesis of schizophrenia in the context of normal brain development and ageing. PNAS. 112 (21) E2745.

Nowrouzi, B., Kamhi, R., Hu, J., Kennedy, J., Matmari, M., De Luca, V., 2015. Age at onset mixture analysis and systematic comparison in schizophrenia spectrum disorders: Is the onset heterogeneity dependent on heterogeneous diagnosis? Schizophr. Res. 164 83-91.

Olfson, M., Ascher-Svanum, H., Faries, D.E., Marcus, S.C., 2011. Predicting psychiatric hospital admission among adults with schizophrenia. Psychiatr. Serv. 62 (10) 1138-1145.

Opler, M., Malaspina, D., Gopal, S., Nuamah, I., Savitz, A.J., Singh, J., Hough, D., 2013. Effect of parental age on treatment response in adolescents with schizophrenia. Schizophr. Res. 151 (1-3) 185-190.

Perälä, J., Saarni, S.I., Ostamo, A., Pirkola, S., Haukka, J., Härkänen, T., Koskinen, S., Lönnqvist, J., Suvisaari, J., 2008. Geographic variation and sociodemographic characteristics of psychotic disorders in Finland. Schizophr. Res. 106 (2-3) 337-347.

Pillas, D., Kaakinen, M., Tzoulaki, I., Netuveli, G., Rodriguez, A., Fung, E., Tammelin, T.H., Blane, D., Millwood, I.Y., Hardy, R., Sovio, U., Pouta, A., Hopstock, L.A., Hartikainen, A.L., Laitinen, J., Vaara, S., Khan, A.A., Chong, R., Elliott, P., Jarvelin, M.-R., 2014. Infant locomotive development and its association with adult blood pressure. Eur. J. Pediatr. 173 (10) 1309-1317.

Ran, M.-S., Chen, S., Chen, E.Y., Ran, B.-Y., Tang, C.-P., Lin, F.-R., Li, L., Li, S.-G., Mao, W.-J., Hu, S.-H., 2011. Risk factors for poor work functioning of persons with schizophrenia in rural China. Soc. Psychiatry Psychiatr. Epidemiol. 46 (11) 1087-1093. 
Rantakallio, P., 1969. Groups at risk in low birth weight infants and perinatal mortality. Acta Paediatr. Scand. 193 (SUPPL) s1-s17.

Rodrigo, G., Lusiardo, M., Briggs, G., Ulmer, A., 1991. Differences between schizophrenics born in winter and summer. Acta Psychiatr. Scand. 84 (4) 320-322.

Smith, G.N., Honer, W.G., Kopala, L., MacEwan, G.W., Altman, S., Smith, A., 1995. Obstetric complications and severity of illness in schizophrenia. Schizophr. Res. 14 (2) 113120.

Social Insurance Institution, 2012. Disability pension 5-12-2012. Retrieved $28^{\text {th }}$ May, 2015, from http://www.kela.fi/web/en/decreased-capacity-for-work_disability pension.

Uggerby, P., Nielsen, R.E., Correll, C.U., Nielsen, J., 2011. Characteristics and predictors of long-term institutionalization in patients with schizophrenia. Schizophr. Res. 131 (1-3) 120126.

World Health Organization (2011). Mental Health Atlas 2011. World Health Organization, Geneva. 
Table 1. The distribution of the working days during the last two years of follow-up in individuals with and without schizophrenia spectrum disorder (SSD).

\begin{tabular}{lllll}
\hline & \multicolumn{2}{c}{ SSD $(\mathrm{n}=161)$} & \multicolumn{2}{c}{ Without SSD (n=10 116) } \\
Working days & $\mathrm{n}$ & $\%$ & $\mathrm{n}$ & $\%$ \\
\hline$<25.0 \%$ & 143 & 88.8 & 2827 & 27.9 \\
$25.0-49.9 \%$ & 5 & 3.1 & 298 & 2.9 \\
$50.0 \%-74.9 \%$ & 5 & 3.1 & 371 & 3.7 \\
$\geq 75.0 \%$ & 8 & 5.0 & 6620 & 65.4 \\
\hline
\end{tabular}


Table 2. Background and early parenthood-related and developmental factors and their association with employment status and hospitalization at last two years of follow-up in individuals with and without schizophrenia spectrum disorders (SSD).

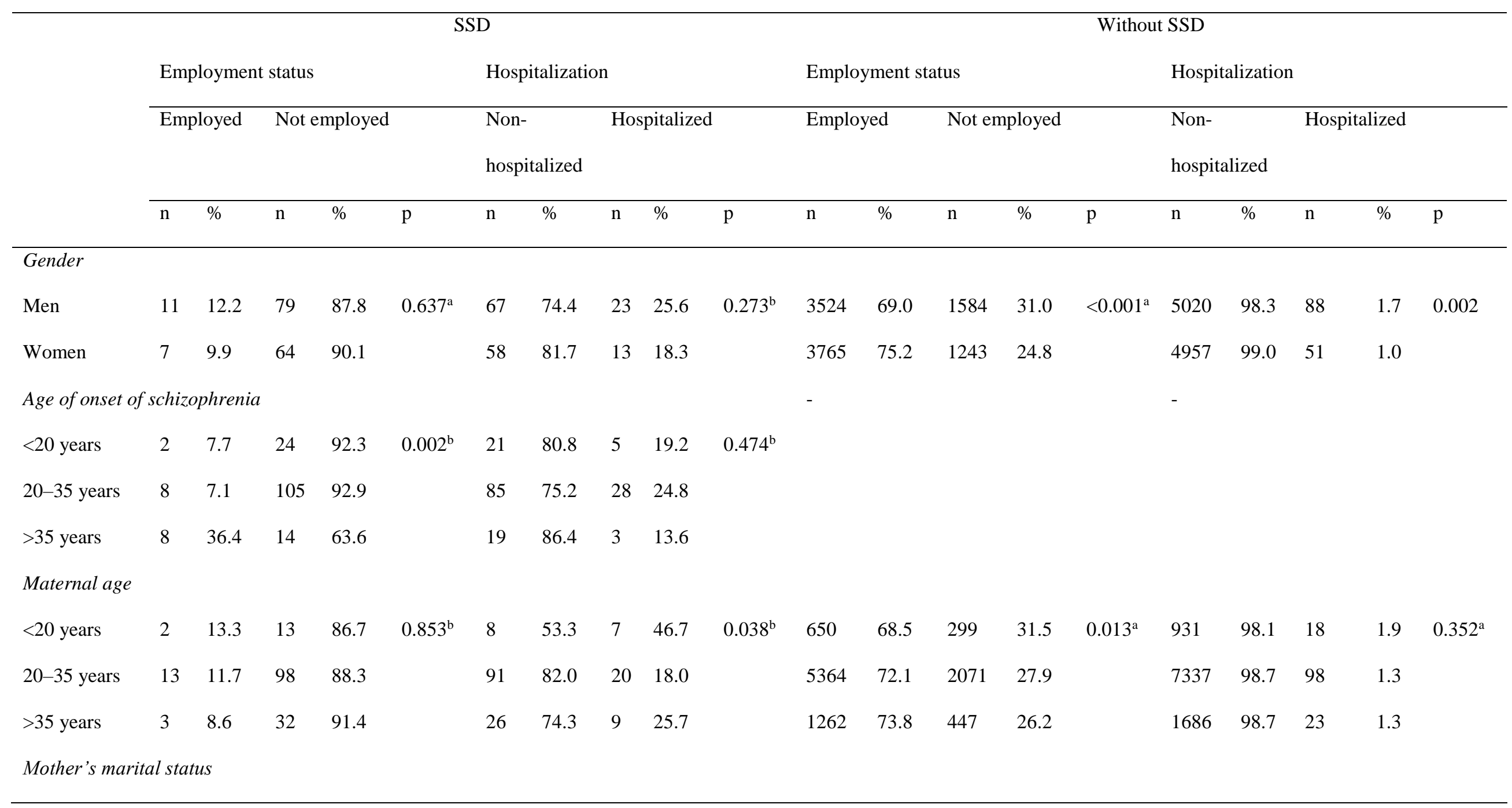




\begin{tabular}{|c|c|c|c|c|c|c|c|c|c|c|c|c|c|c|c|c|c|c|c|c|}
\hline Married & 17 & 11.2 & 135 & 88.8 & $1.000^{\mathrm{b}}$ & 120 & 78.9 & 32 & 21.1 & $0.114^{\mathrm{a}}$ & 7032 & 72.4 & 2684 & 27.6 & $<0.001^{\mathrm{a}}$ & 9589 & 98.7 & 127 & 1.3 & $0.002^{\mathrm{a}}$ \\
\hline Single & 1 & 11.1 & 8 & 88.9 & & 5 & 55.6 & 4 & 44.4 & & 235 & 62.8 & 139 & 37.2 & & 362 & 96.8 & 12 & 3.2 & \\
\hline \multicolumn{21}{|c|}{ Mother's education } \\
\hline $0-8$ years & 10 & 10.5 & 85 & 89.5 & $0.768^{\mathrm{a}}$ & 72 & 75.8 & 23 & 24.2 & $0.615^{\mathrm{b}}$ & 4640 & 70.8 & 1917 & 29.2 & $<0.001^{\mathrm{a}}$ & 6457 & 98.5 & 100 & 1.5 & $0.027^{\mathrm{a}}$ \\
\hline$\geq 9$ years & 7 & 12.1 & 51 & 87.9 & & 46 & 79.3 & 12 & 20.7 & & 2510 & 74.8 & 844 & 25.2 & & 3321 & 99.0 & 33 & 1.0 & \\
\hline \multicolumn{21}{|c|}{ Wantedness of the pregnancy } \\
\hline Wanted & 14 & 11.1 & 112 & 88.9 & $0.738^{\mathrm{a}}$ & 96 & 76.2 & 30 & 23.8 & $0.497^{\mathrm{b}}$ & 6304 & 72.4 & 2405 & 27.6 & $0.240^{\mathrm{a}}$ & 8595 & 98.7 & 114 & 1.3 & $0.616^{\mathrm{a}}$ \\
\hline Unwanted & 2 & 7.1 & 26 & 92.9 & & 23 & 82.1 & 5 & 17.9 & & 807 & 70.7 & 334 & 29.3 & & 1124 & 98.5 & 17 & 1.5 & \\
\hline \multicolumn{21}{|c|}{ Grand multiparity } \\
\hline No & 15 & 11.1 & 120 & 88.9 & $1.000^{\mathrm{b}}$ & 106 & 78.5 & 29 & 21.5 & $0.473^{\mathrm{b}}$ & 6423 & 72.1 & 2484 & 27.9 & $0.703^{\mathrm{a}}$ & 8794 & 98.7 & 113 & 1.3 & $0.011^{\mathrm{a}}$ \\
\hline Yes & 2 & 8.0 & 23 & 92.0 & & 18 & 72.0 & 7 & 28.0 & & 854 & 71.6 & 339 & 28.4 & & 1167 & 97.8 & 26 & 2.2 & \\
\hline \multicolumn{21}{|c|}{ Parental psychoses } \\
\hline No & 13 & 9.6 & 122 & 90.4 & $0.175^{\mathrm{b}}$ & 103 & 76.3 & 32 & 23.7 & $0.351^{\mathrm{b}}$ & 6868 & 72.6 & 2597 & 27.4 & $<0.001^{\mathrm{a}}$ & 9347 & 98.8 & 118 & 1.2 & $<0.001^{\mathrm{a}}$ \\
\hline Yes & 5 & 19.2 & 21 & 80.8 & & 22 & 84.6 & 4 & 15.4 & & 421 & 64.7 & 230 & 35.3 & & 630 & 96.8 & 21 & 3.2 & \\
\hline \multicolumn{21}{|c|}{ Birth weight } \\
\hline$<2,500 \mathrm{~g}$ & 1 & 12.5 & 7 & 87.5 & $1.000^{\mathrm{b}}$ & 7 & 87.5 & 1 & 12.5 & $0.656^{\mathrm{a}}$ & 215 & 64.4 & 119 & 35.6 & 0.006 & 329 & 98.5 & 5 & 1.5 & $0.346^{\mathrm{b}}$ \\
\hline $2,500-$ & 17 & 11.5 & 131 & 88.5 & & 113 & 76.4 & 35 & 23.6 & & 6863 & 72.3 & 2632 & 27.7 & & 9362 & 98.6 & 133 & 1.4 & \\
\hline \multicolumn{21}{|l|}{$4,500 \mathrm{~g}$} \\
\hline$>4,500 \mathrm{~g}$ & 0 & 0 & 5 & 100.0 & & 5 & 100.0 & 0 & 0 & & 202 & 73.5 & 73 & 26.5 & & 274 & 99.6 & 1 & 0.4 & \\
\hline
\end{tabular}




\begin{tabular}{|c|c|c|c|c|c|c|c|c|c|c|c|c|c|c|c|c|c|c|c|c|}
\hline Birth heigh & & & & & & & & & & & & & & & & & & & & \\
\hline$\leq 46 \mathrm{~cm}$ & 2 & 15.4 & 11 & 84.6 & $0.711^{\mathrm{b}}$ & 11 & 84.6 & 2 & 15.4 & $0.759^{\mathrm{a}}$ & 299 & 63.5 & 172 & 36.5 & $<0.001^{\mathrm{a}}$ & 461 & 97.9 & 10 & 2.1 & $0.332^{\mathrm{a}}$ \\
\hline $47-53 \mathrm{~cm}$ & 15 & 10.9 & 123 & 89.1 & & 105 & 76.1 & 33 & 23.9 & & 6522 & 72.2 & 2506 & 27.8 & & 8905 & 98.6 & 123 & 1.4 & \\
\hline$\geq 54 \mathrm{~cm}$ & 0 & 0 & 8 & 100 & & 7 & 87.5 & 1 & 12.5 & & 409 & 75.9 & 130 & 24.1 & & 533 & 98.9 & 6 & 1.1 & \\
\hline
\end{tabular}

a $\chi^{2 \text {-test }}$

b Fisher's Exact Test 
Table 3. Employment status and hospitalization during the last two years of follow up according to different diagnosis of schizophrenia spectrum disorder (SSD).

\begin{tabular}{|c|c|c|c|c|c|c|c|c|c|c|}
\hline \multirow{3}{*}{ SSD } & \multicolumn{4}{|c|}{ Employment status } & \multicolumn{6}{|c|}{ Hospitalization } \\
\hline & \multicolumn{2}{|c|}{ Employed } & \multicolumn{2}{|c|}{ Not employed } & \multicolumn{3}{|c|}{$\begin{array}{c}\text { Non- } \\
\text { hospitalized }\end{array}$} & \multicolumn{2}{|c|}{ Hospitalized } & \\
\hline & $\mathrm{n}$ & $\%$ & $\mathrm{n}$ & $\%$ & $\mathrm{p}$ & $\mathrm{n}$ & $\%$ & $\mathrm{n}$ & $\%$ & $\mathrm{p}$ \\
\hline Schizophrenia & 8 & 6.4 & 117 & 93.6 & $0.001^{\mathrm{a}}$ & 91 & 72.8 & 34 & 27.2 & $0.044^{\mathrm{a}}$ \\
\hline Schizophreniform disorder & 2 & 66.7 & 1 & 33.3 & & 3 & 100.0 & 0 & 0 & \\
\hline Schizoaffective disorder & 4 & 30.8 & 9 & 69.2 & & 13 & 100.0 & 0 & 0 & \\
\hline Delusional order & 4 & 20.0 & 16 & 80.0 & & 18 & 90.0 & 2 & 10.0 & \\
\hline
\end{tabular}


Table 4. Early motor developmental factors and their association with employment status and hospitalization during the last two years of followup [at 45-46 years of age] in individuals with and without schizophrenia spectrum disorder (SSD).

\begin{tabular}{|c|c|c|c|c|c|c|c|c|c|c|}
\hline \multirow[b]{3}{*}{ Age (months) at each developmental } & \multicolumn{5}{|c|}{ Employment status } & \multicolumn{5}{|c|}{ Hospitalization } \\
\hline & \multicolumn{2}{|c|}{ Employed } & \multicolumn{3}{|c|}{ Not employed } & \multicolumn{2}{|c|}{ Non-hospitalized } & \multicolumn{2}{|c|}{ Hospitalized } & \multirow{3}{*}{$\mathrm{p}$} \\
\hline & $\mathrm{n}$ & mean $(\mathrm{SD})$ & $\mathrm{n}$ & mean $(\mathrm{SD})$ & $\mathrm{p}$ & $\mathrm{n}$ & mean $(\mathrm{SD})$ & $\mathrm{n}$ & mean (SD) & \\
\hline milestone & & & & & & & & & & \\
\hline \multicolumn{11}{|l|}{ SSD } \\
\hline Standing up & 9 & $8.2(1.2)$ & 69 & $9.0(1.7)$ & $0.190^{\mathrm{a}}$ & 64 & $8.8(1.6)$ & 14 & $9.2(2.0)$ & $0.455^{\mathrm{a}}$ \\
\hline Standing up without support & 8 & $10.9(1.3)$ & 62 & $11.1(1.4)$ & $0.642^{\mathrm{a}}$ & 57 & $11.1(1.4)$ & 13 & $11.0(1.1)$ & $0.802^{\mathrm{a}}$ \\
\hline Walking without support & 9 & $12.3(1.7)$ & 65 & $12.8(2.2)$ & $0.566^{\mathrm{a}}$ & 57 & $12.7(2.1)$ & 17 & $12.7(2.1)$ & $0.879^{\mathrm{a}}$ \\
\hline \multicolumn{11}{|l|}{ Without SSD } \\
\hline Standing up & 3952 & $8.4(1.4)$ & 1293 & $8.7(1.6)$ & $<0.001^{\mathrm{a}}$ & 5182 & $8.5(1.4)$ & 63 & $8.4(1.8)$ & $0.579^{\mathrm{a}}$ \\
\hline Standing up without support & 3780 & $10.5(1.3)$ & 1205 & $10.7(1.5)$ & $<0.001^{\mathrm{a}}$ & 4919 & $10.5(1.4)$ & 66 & $10.7(1.8)$ & $0.605^{\mathrm{a}}$ \\
\hline Walking without support & 4271 & $11.7(1.6)$ & 1357 & $11.9(2.0)$ & $<0.001^{\mathrm{a}}$ & 5557 & $11.7(1.7)$ & 71 & $11.8(2.0)$ & $0.742^{\mathrm{a}}$ \\
\hline
\end{tabular}

a $t$-test for independent samples 
Table 5. Binary logistic regression analyses for employment and non-hospitalization during the last two years of follow-up according to parenthood-related and developmental factors in individuals with and without schizophrenia spectrum disorder (SSD).

\begin{tabular}{|c|c|c|c|c|c|c|c|c|}
\hline & \multicolumn{4}{|c|}{ SSD } & \multicolumn{4}{|c|}{ Without SSD } \\
\hline & Employment & & Not hospitalized & & Employment & & Not hospitalized & \\
\hline & OR $(95 \% \mathrm{Cl})$ & $\mathrm{OR}(95 \% \mathrm{Cl})$ & OR $(95 \% \mathrm{Cl})$ & OR $(95 \% \mathrm{Cl})$ & $\mathrm{OR}(95 \% \mathrm{Cl})$ & OR $(95 \% \mathrm{Cl})$ & OR $(95 \% \mathrm{Cl})$ & OR $(95 \% \mathrm{Cl})$ \\
\hline & Model 1 & Model 2* & Model 1 & Model 2* & Model 1 & Model 2** & Model 1 & Model 2** \\
\hline Maternal age & - & - & & & & & - & - \\
\hline 20-35 years & & & 1.0 & 1.0 & 1.0 & 1.0 & & \\
\hline$<20$ years & & & $0.25(0.08-0.77)$ & $0.27(0.09-0.85)$ & $0.84(0.73-0.97)$ & $0.84(0.72-0.97)$ & & \\
\hline$>35$ years & & & $0.64(0.26-1.56)$ & $0.71(0.29-1.77)$ & $1.09(0.97-1.23)$ & $1.09(0.97-1.23)$ & & \\
\hline Grand multiparity & - & - & - & - & - & - & & \\
\hline No & & & & & & & 1.0 & 1.0 \\
\hline Yes & & & & & & & $0.58(0.38-0.89)$ & $0.57(0.37-0.88)$ \\
\hline Parental psychosis & - & - & - & - & - & - & & \\
\hline No & & & & & 1.0 & 1.0 & 1.0 & 1.0 \\
\hline Yes & & & & & $0.69(0.59-0.82)$ & $0.69(0.58-0.81)$ & $0.38(0.24-0.61)$ & $0.37(0.23-0.60)$ \\
\hline Birth weight & - & - & - & - & & & - & - \\
\hline $2500 \mathrm{~g}-4500 \mathrm{~g}$ & & & & & 1.0 & 1.0 & & \\
\hline
\end{tabular}




\begin{tabular}{|c|c|c|c|c|c|c|c|c|}
\hline$<2500 \mathrm{~g}$ & & & & & $0.69(0.55-0.87)$ & $0.68(0.54-0.85)$ & & \\
\hline$>4500 \mathrm{~g}$ & & & & & $1.06(0.81-1.39)$ & $1.12(0.86-1.48)$ & & \\
\hline Birth height & - & - & - & - & & & - & - \\
\hline $47-53 \mathrm{~cm}$ & & & & & 1.0 & 1.0 & & \\
\hline$\leq 46 \mathrm{~cm}$ & & & & & $0.67(0.55-0.81)$ & $0.64(0.53-0.78)$ & & \\
\hline$\geq 54 \mathrm{~cm}$ & & & & & $1.21(0.99-1.48)$ & $1.31(1.07-1.60)$ & & \\
\hline Standing up & - & - & - & - & $0.89(0.85-0.93)$ & $0.88(0.85-0.92)$ & - & - \\
\hline Standing up without support & - & - & - & - & $0.92(0.88-0.97)$ & $0.92(0.88-0.96)$ & - & - \\
\hline Walking without support & - & - & - & - & $0.92(0.89-0.95)$ & $0.92(0.88-0.95)$ & - & - \\
\hline
\end{tabular}

*adjusted for sex and onset age

**adjusted for sex 